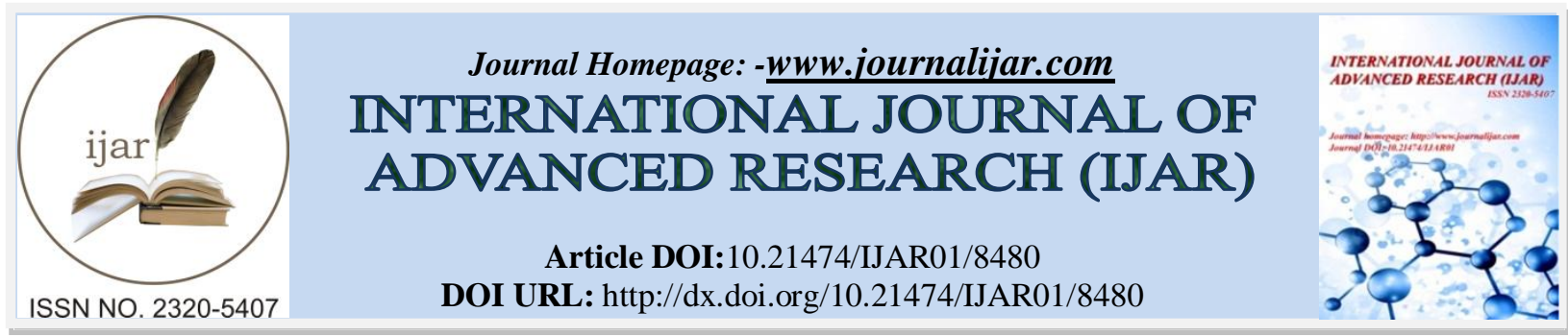

RESEARCH ARTICLE

\title{
EFFICACY OF KARPOORA SILASATTHU PARPAM IN THE MANAGEMENT OF AZHAL KALLADAIPPU (RENAL CALCULI).
}

Nalinisofia. $H^{1}$, Vetha merlin kumari. $H^{2}$ Manickavasakam. $K^{3}$ and Raja rajeswari ${ }^{4}$.

1. Lecturer, Dept.ofMaruthuvam (Medicine), National Institute of Siddha, Chennai.

2. Asso.professor, Dept.ofMaruthuvam (Medicine), National Institute of Siddha, Chennai.

3. Prof. \&HOD, Dept.ofMaruthuvam (Medicine), National Institute of Siddha, Chennai.

4. Asst.Medical officer, ESI Dispensary, Pollachi.

\section{Manuscript Info}

Manuscript History

Received: 02 December 2018

Final Accepted: 04 January 2019

Published: February 2019

\section{Abstract}

Background: Kalladaippu (Kidney stones) is a common problem worldwide with substantial morbidities and economic costs. A large number of people are suffering from urinary stone problem all over the globe. Kidney stones are excruciatingly painful and primarily affect people who are of working age. These patients face not only the cost of treatment, but also the financial difficulties from time off work due to pain and treatment. Recurrent stone formation is a common problem with all types of stones and therefore an important part of the medical care of patients with stone disease. Siddha system of medicine is a great way to treat kidney stones over the years. Siddha formulations indicated for urolithiasis in ancient siddha literatures may have potential antiurolithiatic activity in animal models and also clinically effective in the management of Urolithiasis.

Objective: To evaluate the therapeutic efficacy of a siddha formulation KarpooraSilasathuparpam in the treatment of AzhalKalladaippu (Renal Calculi).

Method: It is an open clinical trial conducted in OPD of AyothidossPandithar Hospital, National Institute of siddha, Chennai for a period of one year. 40 patients diagnosed as AzhalKalladaippu (renal calculi) were included in this study based on the inclusion and exclusion criteria. The test drug Karpoorasilasathuparpam $130 \mathrm{mg}$ was administered with $5 \mathrm{ml}$ of Radish juice orally two times a day after food for 48 days. Result: The mean \pm standard deviation of renal calculi at before and after treatment were $8.30 \pm 3.16$ and $4.2 \pm 4.03$ respectively which is statistically significant $(t=6.092 \mathrm{p}<0.001)$.

Conclusion:The herbo mineral siddha medicine, karpoora silasathu parpam posses the therapeutic effect on renal stone and it is a cost effective siddha formulation will be used in the treatment of early detected kidney stone $>10 \mathrm{~mm}$ without marked obstruction and could avoid surgical intervention.

Copy Right, IJAR, 2019,. All rights reserved. 


\section{Introduction:-}

Kidney stones, one of the most painful of the urologic disorder are not a product of modern life. Kidney Stone disorders are common in men than in women. The highest incidence of kidney stone is in 30-45 years of age group and the incidence declines after the age of 50 years of age. It affects $10-12 \%$ of the population in industrialized countries. Scientists have found evidence of kidney stone in a 7,000 year old Egyptian mummy. Even in the fourth century BC, Hippocrates notes the presents of the renal stone together with renal abscess and he wrote on Hippocrates oath.

Epidemiology of Renal calculi varies according to the geographical areas and socioeconomic conditions. Global climate change is the environmental factor that affects stone disease rates according to research presented at the $103^{\text {rd }}$ Annual Scientific Meeting of the American Urological Association (AUA) and based on the effects of global warming, the percentage of people living in areas designated as high risk for kidney stone formation would increase from $40 \%$ in 2000 to $56 \%$ by 2050 , and up to $70 \%$ by 2095 . This would result in a significant "climate-related" increase in kidney stone events. Renal calculi can be prevented by the most important thing into drink plenty of water daily the goal should be to urinate from two to four liters per day make sure you avoided getting dehydrated, there are no specific dietary recommendation until a stone from your system has been analyzed. After analysis diet can be evaluated and changes recommended.

Although the surgical techniques have taken greater strides, yet the common man in developing country like India may not find it affordable. The formulation KarpooraSilasathu Parpam described in siddha text, Agathiyar chendhooram 300, is mainly indicated for kalladaippu ((Renal calculi). The mode of preparation seems to be simple. The main Ingredients formulation is found to possess Lithotriptic and Diuretic effects and hence this formulation "karpoorasilasathuparpam" was subjected to find out the therapeutic effects in Azhal kalladaippu patients.

\section{Objectives:-}

It is to evaluate the therapeutic efficacy of a siddha formulation KarpooraSilasathu parpam in the treatment of Azhal Kalladaippu (Renal Calculi).

\section{Study design}

It is an open clinical trial conducted in OPD of AyothidassPandithar Hospital, National Institute of siddha, Tambaram sanatorium, Chennai, Tamil nadu, India for a period of one year (2011-2012). 40 patients diagnosed as renal calculi were included in this study based on the inclusion and exclusion criteria.

\section{Inclusion criteria:}

1. Age: $20-60$ Yrs

2. Sex - Both male and female

3. Patients having the classical symptoms of abdominal pain \& distension, pain from loin to groin, pain in urethra, agonizing pain, dysuria, oliguria, yellow coloured urination, burning micturition, haematuria, nausea \& vomiting.

4. Stone size: $\geq 4 \mathrm{~mm}$ to $\leq 10 \mathrm{~mm}$

5. Patient with renal calculus detected on X-ray KUB or USG abdomen.

6. Patient willing to sign the informed consent stating that he/she will conscientiously stick to the treatment during 48days but can opt out of the trial of his/her own conscious discretion.

7. Patients who are willing to take Ultrasonography Investigation (USG- abdomen / KUB) and provide blood for lab investigation.

\section{Exclusion criteria:}

1. Stone size $>10 \mathrm{~mm}$

2. Pregnancy and lactation

3. Presence of any associated severe systemic illness, e.g.CA

4. Patient taking any other lithotriptic agent

5. History of Diabetes/ Hypertension/ Hepatic diseases/ other Renal diseases/ Cardiac diseases

6. History of drug/alcohol abuse 


\section{Conduct of study}

The study was approved by IEC, National Institute of Siddha, Chennai, Tamilnadu (NIS/IEC/2011/3/04). The test drug Karpoorasilasathu parpam $130 \mathrm{mg}$ was administered with $5 \mathrm{ml}$ of Radish juice orally two times a day after food for 48 days. At each visit (once in 15 days) the vital signs, and clinical assessment were recorded in the CRF and medicines were issued. The patients were asked to follow the following dietary regimen and lifestyle modifications during the treatment and follow-up period.

\section{Data management}

After enrolling the patient in the study, a separate file for each patient was opened and all forms were filed in that file. Study No. and Patient No. were entered on the top of file for easy identification. Whenever the study patient visits OPD during the study period, the respective patients file was taken and necessary recordings will be made at the assessment form or other suitable forms. The Data recordings were monitored for completion by the monitoring committee and the adverse events were monitored by the members of the pharmacovigilance department of NIS. All forms were further scrutinized in presence of Investigator by Sr.Research Officer (Statistics) for logical errors and incompleteness of data to avoid any bias. No modification in the results is permitted for unbiased reports.

\section{Withdrawal criteria:-}

1. Intolerance to the drug and development of any serious adverse reactions during the trial period.

2. Poor patient compliance \& defaulters.

3. Patient turned unwilling to continue in the course of clinical trial.

4. Increase in severity of symptoms.

5. Patient will not take medication regularly.

\section{Outcome of the treatment:}

1. The study Outcome is mainly assessed by,

2. Clearance/ reduction in the size of renal calculus in X-ray KUB and USG abdomen.

3. Complete reduction of clinical symptoms and improvement in the lab investigations.

\section{Adverse effect/serious effect management:}

If the trial patient develops any adverse reaction (acute renal colic i.e. severe pain caused by the kidney stoneand associated with nausea, vomiting and fever) he/she will be referred to the pharmacovigilance department of NIS. The members of this department will assess the adverse event and recorded in the prescribed adverse reaction form. For any AE the investigator will be given the proper management in NIS OPD with free of cost.

\section{Statistical analysis:}

All collected data will be entered into the computer and manually cross-checked the correctness of the data entry. The clinical symptoms and size of the stone will be analyzed by comparing the two point of data (before and after treatment) paired test and chi-square test will be employed to study the efficacy of treatment.

\section{Results:-}

\section{Distribution of cases by gender:-}

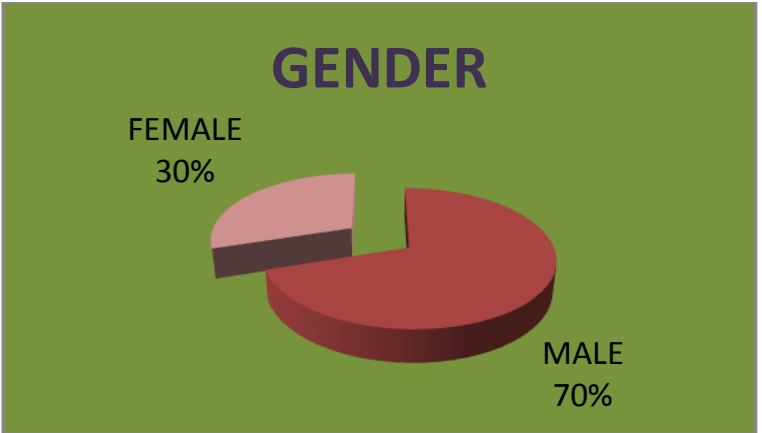

Among the 40 cases the prevalence of the disease was found to be higher in male. i.e. $70 \%$ ( 28 cases). 
Age:-

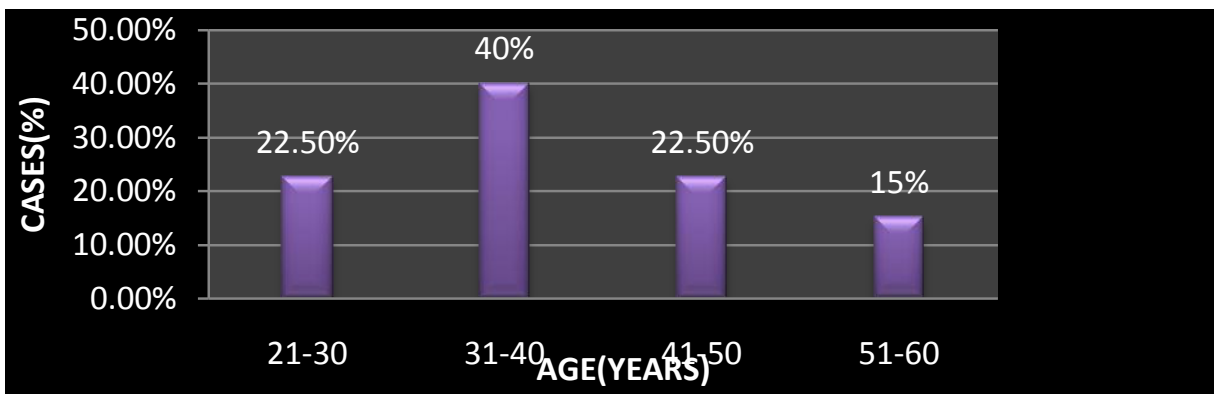

The prevalence of the disease was found to be higher in the age group 31 - 40 years. i.e, 16 cases (40\%).

Distribution of cases by kaalam (life span):-

\begin{tabular}{|l|l|l|}
\hline KAALAM & NO. OF CASES & PERCENTAGE (\%) \\
\hline Vathakaalam (upto 33years) & 15 & 37.5 \\
\hline Pithakaalam (33-66 years) & 25 & 62.5 \\
\hline Kabakaalam (66-100 years) & 0 & 0 \\
\hline
\end{tabular}

Out of 40 cases, 25 cases (62.5\%) were found to be in Pithakaalam i.e. between 33 - 66 years and 15 cases (37.5\%) were in vathakaalam.

\section{Food habits:-}

Among the 40 cases 38 cases (95\%) were Non vegetarians and 2 cases (5\%) were vegetarian.

Paruvakaalam (season):-

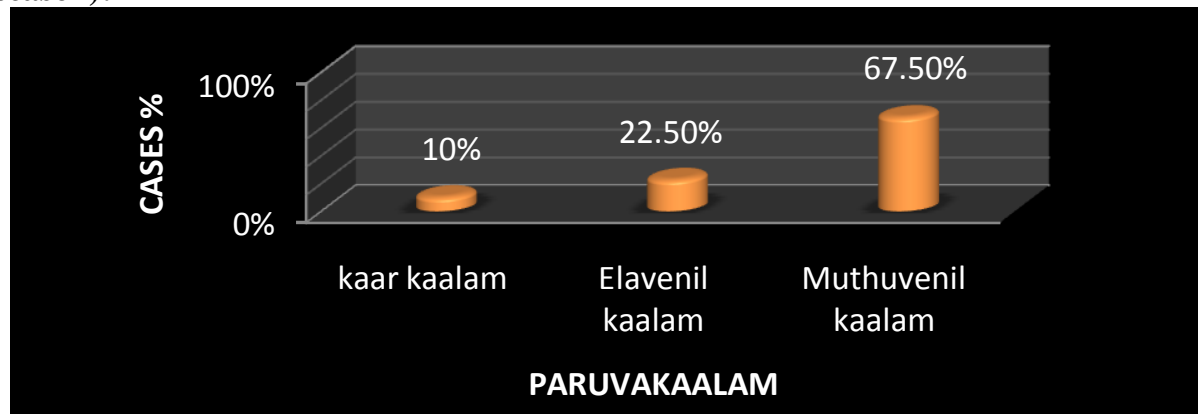

Among the 40 cases 27 cases (67.5\%) were admitted in Muthuvenilkaalam (later summer), 9 cases (22.5\%) were admitted in Elavenilkaalam (early summer) and 4cases (10\%) were admitted in kaarkaalam (rainy season).

Thinai (land):-

Among the 40 cases 39 cases (97.5\%) were from Neithalthinai(Maritime tracts), and 1 case (2.5\%) was from Maruthamthinai(Agricultural tracts).

Occupational status:-

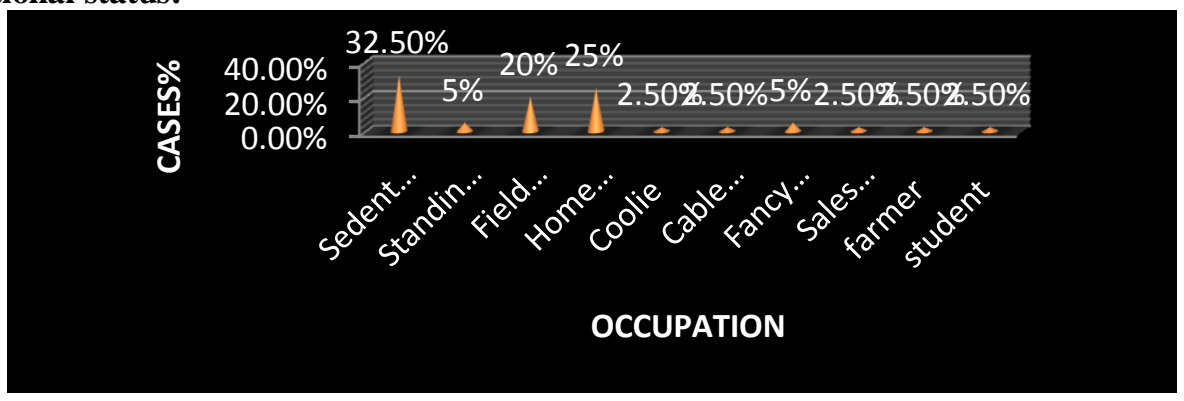


Among the 40 patients, 13 cases $(32.5 \%)$ were sedentary work style. 10 cases $(25 \%)$ were home maker. 8 cases $(20 \%)$ were field work and 2 cases $(5 \%)$ were standing work and fancy article vender. Rest of 1case $(2.5 \%)$ were Coolie, Cable TV operator, Sales executive and farmer.

Treatment history (before admitted to the trial) :-

\begin{tabular}{|l|l|l|}
\hline TREATMENT HISTORY & NO OF CASES & PERCENTAGE (\%) \\
\hline H/O Allopathy medicine taken & 26 & 65 \\
\hline No H/O anyMedication & 14 & 35 \\
\hline Total & 40 & 100 \\
\hline
\end{tabular}

Among the 40cases, 26cases $(65 \%)$ had taken allopathic treatment in the past and had discontinued the same. The rest of the 14 cases $(35 \%)$ had not taken any other drugs prior to enrolling for the study.

\section{Duration of illness}

\begin{tabular}{|l|l|l|}
\hline DURATION IN MONTHS & NO. OF CASES & PERCENTAGE \% \\
\hline 0 to 3 & 29 & 72.5 \\
\hline 4 to 6 & 10 & 25 \\
\hline 7 to 9 & 0 & 0 \\
\hline Above 9 & 1 & 2.5 \\
\hline Total & 40 & 100 \\
\hline
\end{tabular}

Among the 40 cases majority of them were 0 to 3 months in their duration of illness, i.e, 29 cases (72.5\%), 10cases $(25 \%)$ had the illness in 4 to 6 months and 1 case $(2.5 \%)$ was above 9 months.

Clinical features:-

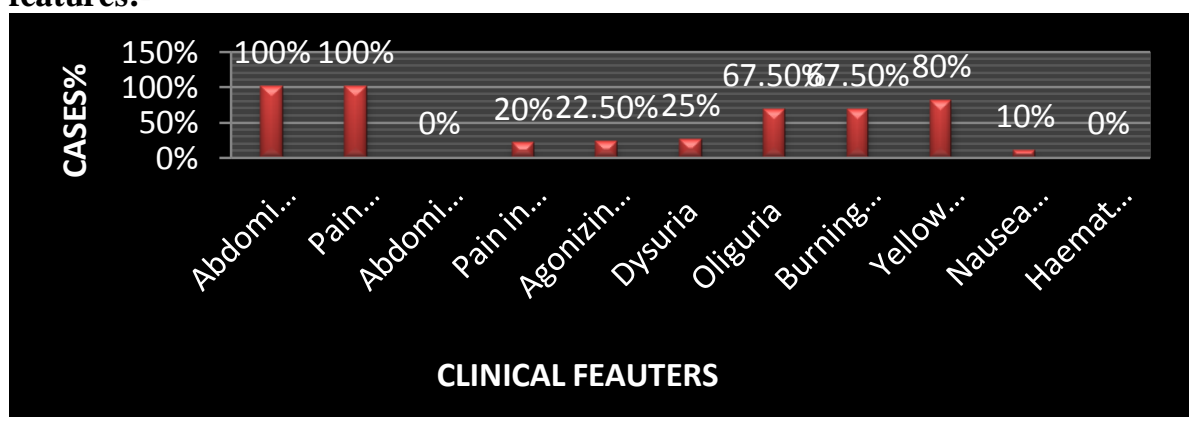

All the 40 cases $(100 \%)$ had abdominal pain and pain from loin to groin region. 32cases(80\%) had yellow coloured urination. 27cases $(67.5 \%)$ had oliguria and burning micturition. 10cases $(25 \%)$ were affected by dysuria. 9cases $(22.5 \%)$ were affected by agonizing pain. 8cases $(20 \%)$ had pain in urethra and 4cases $(10 \%)$ had nausea and vomiting.

Mukkutram (Three vital humours):-

Vatham:-

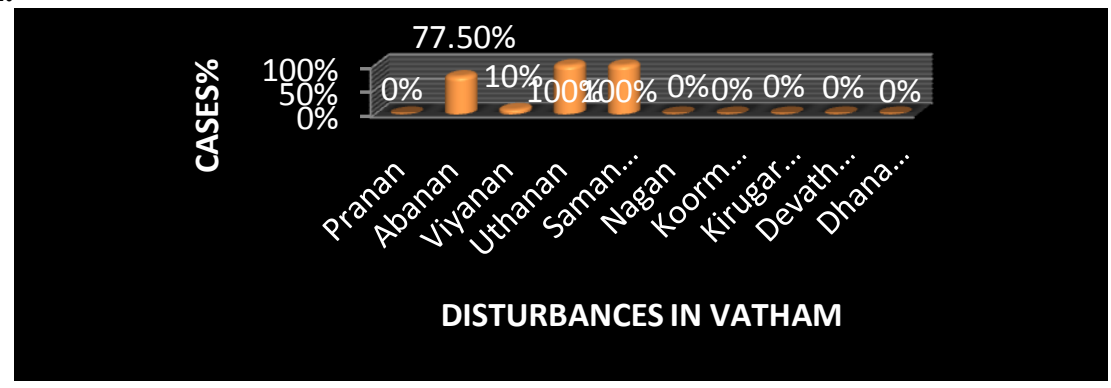

Out of 40 cases observed, viyanan was affected in all the 40 cases (100\%) also samanan was affected in all the 40 cases $(100 \%)$ because it controls the other types of vathas. Abanan was affected in 31cases $(77.5 \%)$. 


\section{Pitham:-}

Out of 40 cases, saathagapiththam was affected in all the cases (100\%) due to routine duty off because of abdominal pain. In presence of nausea and vomiting Anarpitham was affected in 4 cases (10\%).

\section{Kabam:-}

Out of 40 cases pothagam was affected in 4 cases (10\%) due to nausea and vomiting

\section{Naadi (Pulse):-}

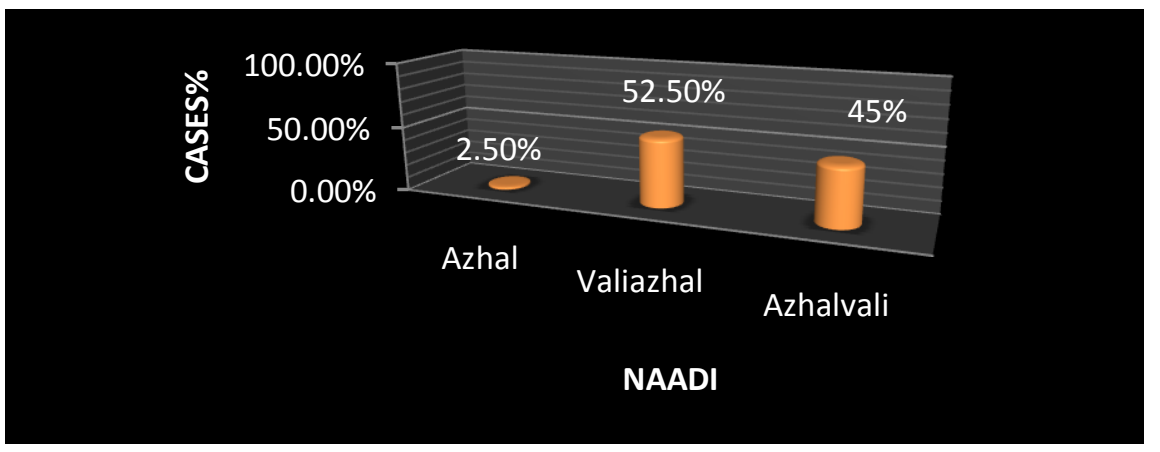

Among the 40 cases valiazhalnaadi was felt in 21 cases $(52.5 \%)$, azhalvalinaadi was felt in 18 cases (45 $\%)$,azhalnaadi was felt in 1 case $(2.5 \%)$.

\section{Neerkuri (urine analysis):-}

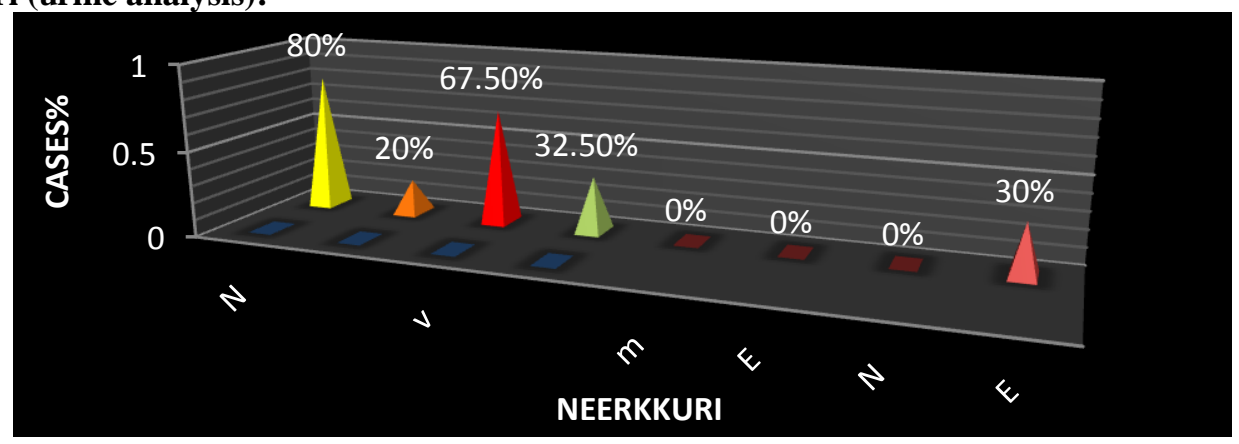

Out of 40 cases, yellow coloured was observed in 32 cases (80\%) and straw coloured was in 8cases (20\%). The volume of urine was reduced amount in 27 cases $(67.5 \%)$, rest of 13 cases $(32.5 \%)$ had normal urine volume. Enjal was found to be in 12 cases (30\%) in the presence of bacterial infections. No other changes were observed in Manam, Edai and Nurai.

Neikkuri (oil sign in urine):-

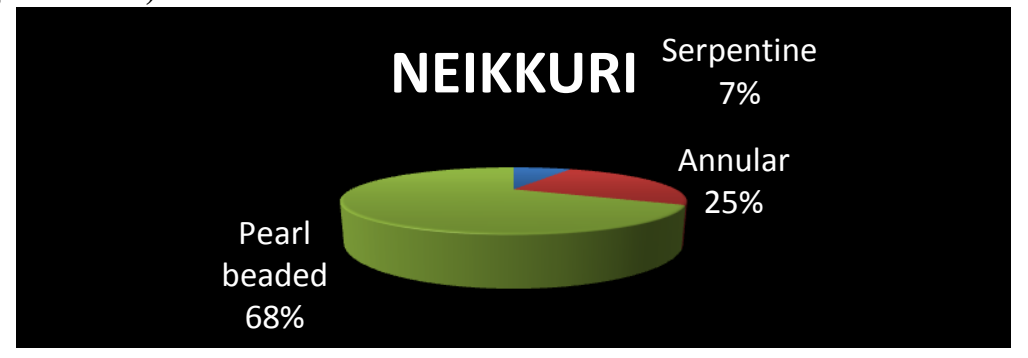

Among the 40 cases, neikkuri was observed in 27 cases (67.5\%) as pearl like. In 10cases (25\%) the neikkuri was observed as Annular like and in 3cases (7.5\%) neikkuri was observed as serpentine like 
Calculus in urinary system

\begin{tabular}{|l|l|l|}
\hline SITE OF CALCULUS & NO OF CASES & PERCENTAGE \% \\
\hline Both kidneys & 15 & 37.5 \\
\hline Right kidney & 7 & 17.5 \\
\hline Left kidney & 6 & 15 \\
\hline Ureter & 12 & 30 \\
\hline
\end{tabular}

Out of 40 cases, 15 cases (37.5\%) had bilateral renal calculi, 13 cases (32.5\%) had unilateral renal calculi, out of them 7 cases $(17.5 \%)$ in right kidney and 6 cases $(15 \%)$ in left kidney. 12cases $(30 \%)$ had ureteric calculi.

Urine culture and sensitivity:-

\begin{tabular}{|l|l|l|l|}
\hline \multicolumn{2}{|l|}{ Culture and sensitivity } & No of cases & Percentage (\%) \\
\hline Before treatment & 12 & 30 \\
\hline \multirow{2}{*}{ After treatment } & No growth & $5 / 12$ & 41.7 \\
\cline { 2 - 4 } & Grown in culture & $7 / 12$ & 58.3 \\
\hline
\end{tabular}

Among the 40 cases, 12cases (30\%) had Bacterial infections in urine culture before treated with trial drug. Out of them 5 cases $(41.7 \%)$ were found to be no bacterial infections in urine culture after the completion of the trial drug treatment and 7 cases $(58.3 \%)$ had grown in culture.

Hydroureteronephrosis:-

\begin{tabular}{|l|l|l|l|}
\hline \multicolumn{2}{|l|}{ Hydroureteronephrosis } & No of cases & Percentage (\%) \\
\hline Before treatment & 12 & 30 \\
\hline \multirow{2}{*}{ After treatment } & Relieved & $7 / 12$ & 58.3 \\
\cline { 2 - 4 } & Not relieved & $5 / 12$ & 41.7 \\
\hline
\end{tabular}

Before treated with trial drug 12 cases (30\%) had hydrouretronephrosis. Among them, 7cases (58.3\%) were relieved from hydrouretronephrosis after the treatment with trial drug and 5 cases $(41.7 \%)$ were not relieved.

\section{Result of USG KUB after treatment:-}

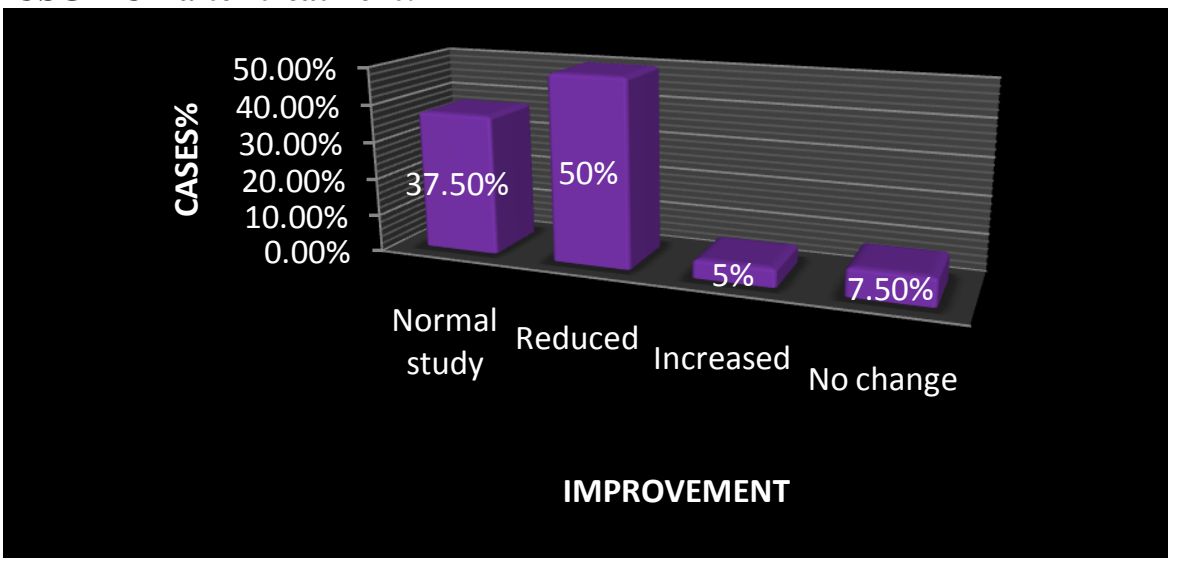

Out of 40 cases, 15 cases (37.5\%) showed normal study, i.e. Stone completely dissolved. 20cases (50\%) showed reduce its size and number. 2 cases $(5 \%)$ showed increase in size and 3 cases $(7.5 \%)$ showed no changes in size. 
Clinical features before and after treatment:-

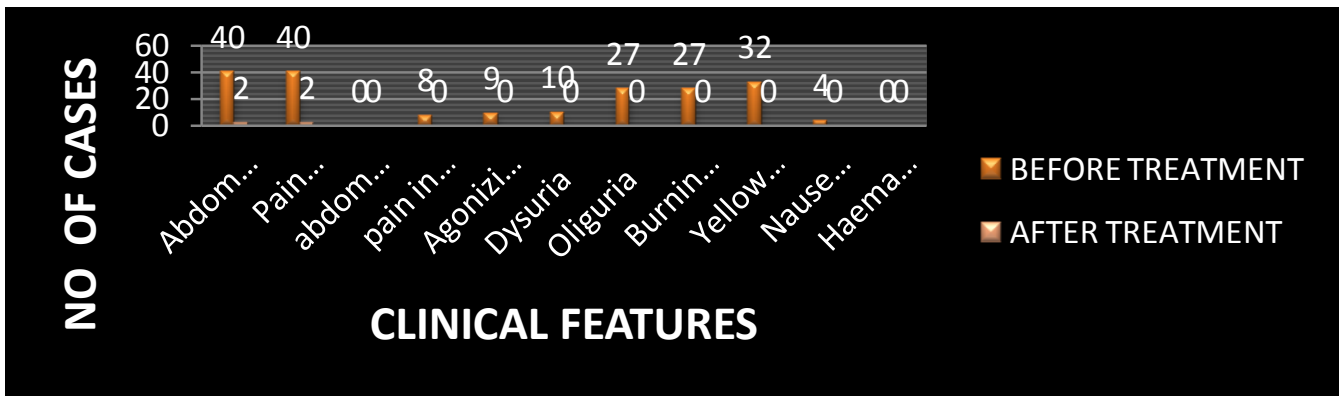

After treatment 38 cases had relieved from abdominal pain and loin pain. Rest of the other symptoms such as abdominal distension, pain in urethra, agonizing pain, dysuria, oliguria, yellow coloured urination, burning micturition, nausea and vomiting, haematuria were relieved in $100 \%$ of cases.

\section{Statistical analysis}

Mean and Standard deviation was used to test the significance of treatment using before and after treatment data on Renal Calculi and Symptoms.

The level of significance probability 0.05 was used to test the treatment difference and the values are statistically significant.

Mean and Standard deviation of Renal calculi at before and after treatment

\begin{tabular}{|l|l|l|l|l|l|}
\hline variable & Mean & Std. Deviation & Std. Error Mean & t value & p value \\
\hline BTRLK & 8.302 & 3.1685 & .5010 & 6.092 & $\mathrm{P}<0.001$ \\
\cline { 1 - 2 } & 4.200 & 4.0324 & .6376 & & \\
\hline
\end{tabular}

BTRLK - before treatment right left kidney, BTRLK - after treatment right left kidney

The mean \pm standard deviation of renal calculi at before and after treatment were $8.30 \pm 3.16$ and $4.2 \pm 4.03$ respectively which is statistically significant $(\mathrm{t}=6.092 \mathrm{p}<0.001)$.

Mean and Standard deviation of clinical Symptoms before and after treatment

\begin{tabular}{|l|c|l|l|l|l|}
\hline Clinical Symptoms & Mean & Std.Deviation & Std. Error Mean & T value & P value \\
\hline Before treatment & 4.95 & 1.894 & 0.299 & 7.525 & \\
\hline After treatment & 2.93 & 0.656 & 0.104 & & \\
\hline
\end{tabular}

The mean \pm standard deviation of symptoms score at before and after treatment were $4.95 \pm 1.89$ and $2.93 \pm 0.66$ respectively which is statistically highly significant $(\mathrm{t}=7.5 \mathrm{p}<0.0001)$ i.e. the symptoms have been reduced significantly after the treatment.

Stone expulsion:-

OP No: C84030 Age/Sex: 38/M Stone size: 5mm

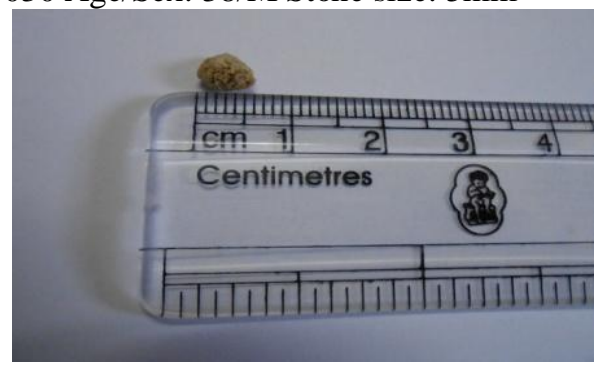



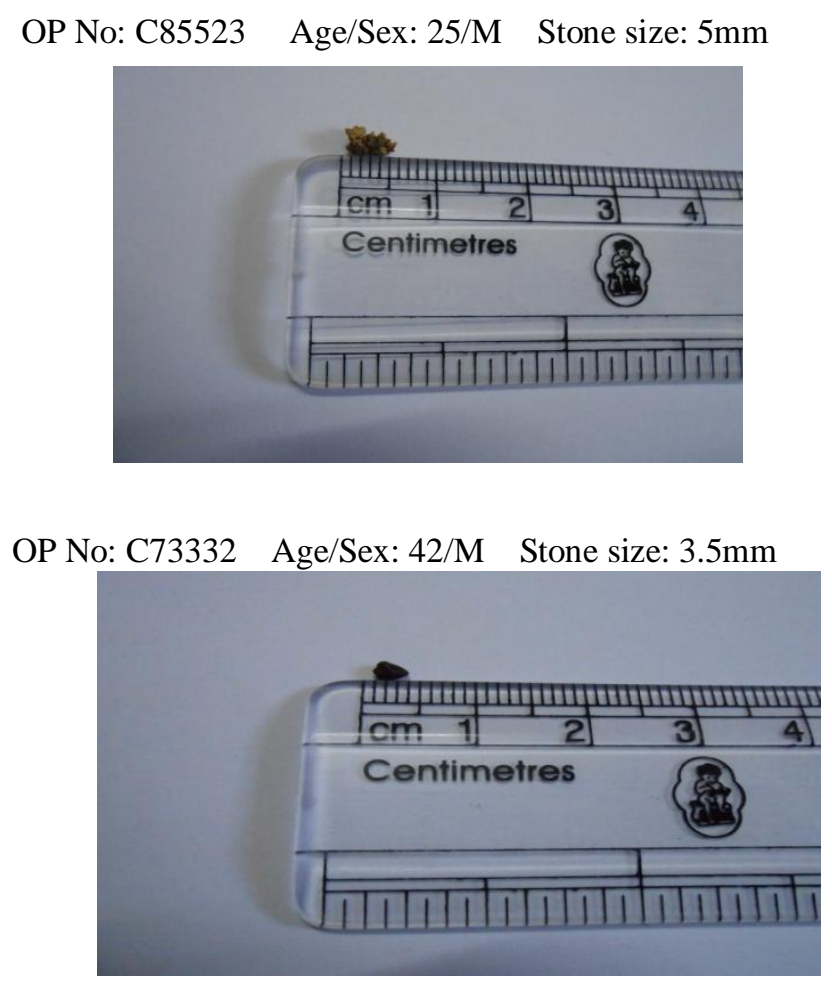

\section{Discussion:-}

The main aim of the treatment was to study the therapeutic effect of the drug Karpoorasilasathuparpam in the disease Azhalkalladaippu (Renal calculi). The clinical features of Azhalkalladaippu can be correlated to Renal Calculus in Modern science. As per yougivaithiyachinthamani text, Azhalkalladaippu is characterized by oliguria, urethral pain mimics a pain caused by an insertion of burning iron bar in the urethra, sweating all over body, anuria, agonizing pain, blood stained calculus stagnated in urethra.

The majority affected sex was male i.e., 28 cases (70\%) and female was 12cases (30\%). Males are affected 3 times as frequently as females, because Testosterone appears to promote stone formation by suppressing osteopontin expression in the kidneys and increasing urinary oxalate excretion and Testosterone may cause increased oxalate production in the liver (predisposing to calcium oxalate stones) and women have higher urinary citrate concentrations (citrate inhibits calcium oxalate stone formation).

This study showed that the highest incidence of Azhalkalladaippu was between 31 - 40 years of age, i.e. 16 cases (40\%). The peak incidence of renal calculi occurs between 20 and 40 years of age. As per the Rathinasurukkanaadi these period is mainly in pithakaalam (33 - 66 years) of human life. All the 40 cases under this analysis were predominantly of Rajogunam assessed from interrogation and other observations. Among the 40 patients, 25 cases (62.5\%) were found to be in pithakaalam (34-66 yrs) and 15cases (37.5\%) in vathakaalam (upto 33 years). The peak incidence of renal calculi occurs between 20 and 40 years of age. In this study, 27 cases $(67.5 \%)$ were reported in muthuvenilkaalam, 9cases (22.5\%) in Elavenilkaalam and 4cases (10\%) in Kaarkaalam. In Muthuvenilkaalam, vatham is vitiated and Iyam comes to normal. In Elavenilkaalam, Iyyam is vitiated. Environmental temperature associated with stone formation was more common in the summer months. This tendency may be due to relative dehydration and the subsequent production of concentrated, acidic urine. Alternatively some workers suggest the increased exposure to sunshine leads to increased urinary calcium excretion. Ureteric stones become more prevalent during the summer, the highest incidence occurring a month or so after peak summertime temperatures, presumably because of higher urinary concentration in the summer (encourages crystallization). Concentrated urine has a lower $\mathrm{pH}$, encouraging cystine and uric acid stone formation. 
In this study, $90 \%$ of cases were reported from Neithal land. In Siddha literatures, it was mentioned that Neithal is a land, which is responsible for vaatha diseases. Mineral contents of water in this Neithal land may contribute to the formation of kidney stone.

Sedentary work style may accounts for the highest number of 13cases (\%). Sedentary occupations predispose to stones compared with manual workers. The risk of calcium oxalate and uric acid stones formation in Astronauts because of decreased $\mathrm{pH}$ and lower urinary volumes.

Among the 40 cases 38 cases (95\%) were non-vegetarians (mainly animal protein and fat substances). Animal protein contains oxalates, calcium, phosphates and other elements often lead to an excess excretion of them in urine. High intake of animal protein causes high urinary oxalate, low pH, low urinary citrate, and High salt intake causes hypercalciuria. However, a reduced calcium diet can increase the risks of further stone formation.

Viyanan and samanan were affected in all the 40 cases (100\%) because of abdominal pain and pain from loin to groin region. Abanan was affected in 31cases (77.5\%) in the presence of burning micturition, dysuria and oliguria. Saathagapiththam was affected in almost all the cases $(100 \%)$ due to routine duty off by the abdominal pain. Anarpitham was affected in 4 cases $(10 \%)$ in the presence of nausea and vomiting. Pothagam was affected in 4 cases $(10 \%)$ because of nausea and vomiting.

Valiazhalnaadi was felt in 21 cases (52.5\%), azhalvalinaadi was felt in 18 cases (45\%), azhal naadi was felt in 1 case $(2.5 \%)$. On examination by Envagaithervugal, the moothiram has been affected in all patients due to derangement of Vatham and pitham. Yellow coloured was observed in 32 cases $(80 \%)$ and straw coloured was in 8 cases $(20 \%)$. The volume of urine was reduced the amount in 27 cases $(67.5 \%)$, rest of 13 cases $(32.5 \%)$ had normal urine volume. Enjal was found to be in 12 cases (30\%). No other changes were observed in Manam, Edai and Nurai. In 27cases (68\%) oil was spread slowly like pearl shape. In 10cases (25\%) it was annular/ring and in 3cases $(7 \%)$ it was serpentine like. Among the 40 cases, 12cases $(30 \%)$ had Bacterial infections in urine culture ((E.Coli, Klebsiella, and Pseudomonas) before treated with trial drug. Out of them 5cases (41.7\%) were found to be no bacterial infections in urine culture after the completion of the trial drug treatment and in 7 cases $(58.3 \%)$ the same organism had grown in culture.

Before treated with trial drug 12 cases (30\%) had hydrouretronephrosis. Among them, 7cases $(58.3 \%)$ were relieved from hydrouretronephrosis after the treatment with trial drug and 5 cases $(41.7 \%)$ were not relieved.

All the 40 patients were taken ultrasonography,

1. Among the 40 cases stone completely dissolved in 15 patients (Ureteric calculus, Renal calculus + Ureteric calculus)

2. Size and number of stone is reduced in 20 patients (Renal calculus).

3. In 5 patients there was no change in size of stone but clinical symptoms were completely relieved.

Abdominal pain and loin pain were relieved in 38 cases (95\%) other symptoms such as abdominal distension, pain in urethra, agonizing pain, dysuria, oliguria, yellow coloured urination, burning micturition, nausea and vomiting, haematuria were relieved in all the 40 cases $(100 \%)$.

Among 40 cases, prior to treatment patients had elevated levels of serum Calcium, phosphorus and uric acid. However, they were within the range considered to be normal. Subsequent to treatment, patients demonstrated reduced levels in all the three parameters.

Among 40 cases,

1. In $32(80 \%)$ of cases there was reduction in Serum Calcium after treatment.

2. In $31(77.5 \%)$ of cases there was reduction in Serum phosphorus after treatment.

3. In $34(85 \%)$ of cases there was reduction in Serum uric acid after treatment.

Karpoorasilasathu acts as a diuretic and Lithotriptic agent and is mainly indicated in the management of renal calculi, Burning micturition and anuria. It diminishes Phosphaturia and it may be usefull in Phosphatic calculus.

\section{Conclusion:-}

This clinical study analyzed the prevalence of renal stone, various causes and risk factors associated with renal stone disease. The test drug karpoorasilasathuparpamposses the therapeutic effect on renal stone and it is a cost effective 
herbo mineral siddha formulation will be used in the treatment of early detected kidney stone $>10 \mathrm{~mm}$ without marked obstruction and could avoid surgical intervention.

\section{References:-}

1. K.S.Uthamarayan HPIM, siddha maruthuvangasurukkam, $2^{\text {nd }}$ Edition, 2006.

2. Dr.K.Anbarasu, agathiyarchendhooram 300moolamumuraiyum $1^{\text {st }}$ edition, 1998.

3. Dr.M.Shanmugavelu, Noinadalnoimudhalnadalthirattu, part $2,3^{\text {rd }}$ edition, 2003.

4. Dr.K.N.KuppusamyMudhaliyar, Siddha MaruthuvamPothu, $7^{\text {th }}$ edition, 2007.

5. T.V.Sambasivam pillai, Tamil and English dictionary, volume2, 4 \& 5.

6. Dr. G. Durairasan, Siddha principles of social and preventive medicine.

7. Guyton \& hall, Textbook of medical physiology, $11^{\text {th }}$ edition.

8. Sarathasubramaniam, Textbook of human physiology.

9. K. Sembulingam Essential of medical physiology $5^{\text {th }}$ edition.

10. P.M. Venugopal, Udalthathuvam, $3^{\text {rd }}$ edition, 1993.

11. Davidson's Principle and practical of medicine, $21^{\text {st }}$ edition.

12. R.Alagappan, Manual of Practical Medicine $4^{\text {th }}$ edition

13. Nalinisofia.H, Manickavasakam. K A pilot study evaluating Therapeutic efficacy of Siddha formulation Nandukkalparpam in the management of Renal calculi. Current Traditional Medicine, Volume 1, Issue 2

14. Nalinisofia.H, Manickavasakam. K, Thomas M. Walter, Prevalence and Risk factors of Kidney stone, Global Journal for Research Analysis, Volume 5, Issue 3.

15. Global Warming May Lead To Increase In Kidney Stones Disease Science Daily (May 15, 2008)

16. Smith and Tanagho's General urology, 18thedition, The McGraw-Hills companies USA

17. R. Thiyagarajan, 'GunapadamThathuJeevaVaguppu' Sixth edition, published by Directorate of Indian Medicine and Hoemopathy, Chennai, India (2006).

18. Nalinisofia.H, Vetha merlin kumari.H, Thomas M. Walter, Mohan.S. Preliminary clinical study of siddha formulations in the treatment of kalladaippu (urolithiasis). 